\title{
Diálogos sobre história oral: limites e possibilidades
}

Dialogues about oral history: limits and possibilities

Francisco Marcos Mendes Nogueira ${ }^{1}$

1 Universidade Federal do Rio Grande do Sul - UFRGS, E-mail: marcos2201@gmail.com, ORCID: https://orcid.org/0000-0002-1630-5613

\section{ARTICLE INFO}

Article history:

Received 2021-06-21

Accepted 2021-08-02

Available online 2021-08-02

\section{Palavras-chave:}

História Oral. Limites. Possibilidades.

Keywords: Oral History; Limits; Possibilities.

RESUMO. O presente texto versa sobre os limites e as possibilidades da História Oral $(\mathrm{HO})$, especialmente nas pesquisas realizadas no campo das Ciências Humanas e Sociais. Assim, nosso o ponto de partida se dá, a priori, com a compreensão de que a HO é um procedimento metodológico e, ao mesmo tempo, um meio em que o (a) pesquisador (a) lança mão a fim de (re) constituir testemunhos, versões e/ou interpretações da ação dos sujeitos históricos, bem como para produzir conhecimentos históricos. Posto isso, vale sublinhar o lugar de fala deste texto, a qual se deu/dar com experiência do minicurso Diálogos sobre história oral: limites e possibilidade, ofertado na II Jornada de Gênero, Cultura e Deslocamentos, no mês de abril de 2021. Devido à pandemia do Coronavírus (COVID-19), o evento aconteceu na modalidade remota através do Google Meet. A metodologia do minicurso buscou privilegiar a dialogicidade com base na discussão de texto pré-selecionados (Montenegro, 2003; Delgado, 2003; 2006; Alberti, 2007; 2014; Portelli, 1997; 2005; 2010; 2016), exibição do filme Narradores de Javé. Ao final, foi possível depreender que, embora, a metodologia da $\mathrm{HO}$ seja uma ferramenta metodológica atraente, ela tem seus limites, desafios e percalços.

ABSTRACT. This text deals with the limits and possibilities of Oral History $(\mathrm{OH})$, especially in research carried out in the field of Human and Social Sciences. Thus, our starting point is, a priori, with the understanding that $\mathrm{OH}$ is a methodological procedure and, at the same time, a means in which the researcher uses in order to (re) to constitute testimonies, versions and/or interpretations of the actions of historical subjects, as well as to produce historical knowledge. It is worth underlining the place of speech of this text, which was given/given with the experience of the mini-course Dialogues on oral history: limits and possibilities, offered at the II Journey on Gender, Culture and Displacements, in April 2021. Due to the Coronavirus pandemic (COVID- 
19), the event took place remotely via Google Meet. The methodology of the short course sought to privilege dialogues based on the discussion of pre-selected texts (Montenegro, 2003; Delgado, 2003; 2006; Alberti, 2007; 2014; Portelli, 1997; 2005; $2010 ; 2016)$, showing the movie Yahweh narrators. It is possible to infer that, although the $\mathrm{OH}$ methodology is an attractive methodological tool, it presents its limits, challenges and drawbacks.

\section{Introdução}

"Em sua forma mais elementar, as narrativas orais e os testemunhos que constituem a história oral não são mais do que uma ferramenta adicional na panóplia de fontes do historiador - e, assim, estão sujeitas ao mesmo escrutínio crítico que todas as outras fontes, a fim de averiguar sua confiabilidade e usabilidade"

Alessandro Portelli, 2016, p. 9

À primeira vista, a temática do minicurso - Diálogos sobre História Oral: limites e possibilidade - pareceu-me bastante "batida" e, em certa medida, eu fiquei até receoso de propô-lo. Tal não foi a minha surpresa ao fim das inscrições para a II Jornada de Gênero, Cultura e Deslocamentos, da Universidade Estadual de Roraima (UERR). Havia um bom número de pessoas interessadas na temática e no debate acerca dos limites e possibilidades da aplicabilidade da metodologia da História Oral (HO), especialmente nas pesquisas na área das Humanidades.

Salienta-se que, devido à pandemia do Coronavírus (Covid-19), a II Jornada aconteceu na modalidade remota através do Google Meet. Essa realidade exigiu da coordenação um esforço maior, além de mobilizar um maior número de pessoas para colaborar com e no evento, como é o caso dos monitores do nosso minicurso, os mestrandos ${ }^{1}$ Lucenir Lucena Ferreira e José Domingos Alves dos Santos.

É preciso destacar, para além dos desafios que a modalidade remota nos exigiu, visto que também oportunizou e facilitou a participação de pessoas que não residem em Roraima, as quais puderam apresentar seus trabalhos de pesquisa ou mesmo participar dos minicursos. A título de exemplo dessa participação podemos

\footnotetext{
1 Os monitores são mestrandos do Mestrado Acadêmico em Educação. O curso é uma iniciativa de associação interinstitucional entre a Universidade Estadual de Roraima (UERR) e Instituto Federal de Educação, Ciência e Tecnologia de Roraima (IFRR).
} 
citar que se fizeram presentes pessoas da Bahia, Brasília, Pará, Goiás, entre outros estados brasileiros. Além de um participante de Montevidéu, capital do Uruguai.

Posto isso, o presente texto versa sobre a nossa experiência com o minicurso, o qual buscou discutir os limites e as possibilidades da História Oral. Para tanto, demarca-se como ponto de partida a compreensão de que a $\mathrm{HO}$ é um procedimento metodológico e, ao mesmo tempo, um meio em que o (a) pesquisador (a) lança mão a fim (re) constituir testemunhos, versões e/ou interpretações da ação dos sujeitos históricos, bem como para produzir conhecimentos históricos.

\section{Procedimentos metodológicos}

A proposta metodológica do minicurso "Diálogos sobe história oral: limites e possibilidades" teve como fundamento a dialogicidade, no qual buscou-se envolver os participantes no debate a partir das discussões sobre $\mathrm{HO}$, tendo mediação epistemológica autores, como Antônio Torres Montenegro (2003), Lucília de Almeida Neves Delgado (2003; 2006) Verena Alberti $(2007 ; 2014)$ e Alessandro Portelli (1997; 2005; 2010; 2016).

Além dos textos, ocorreu a exibição do filme brasileiro "Narradores de Javé". O filme narra a "história" de um vilarejo chamado Javé, o qual está prestes a ser destruído por causa da construção de uma Hidrelétrica. Com o fim iminente do vilarejo, os moradores buscam uma alternativa para evitar a destruição do local.

A ideia da utilização do filme foi evidenciar como há uma relação entre memórias, história e narrativas sobre o passado, as quais são atualizadas no tempo presente, pois como afirma Delgado (2006, p. 16) "o passado espelhado no presente, reproduz através de narrativas, a dinâmica da vida pessoal em conexão com processos coletivos".

\section{Desenvolvimento}

O nosso ponto de partida se deu com alguns questionamentos aos participantes do minicurso, a saber: o que é história oral? A história oral consegue responder a todas as questões de pesquisa no campo das Ciências Humanas e Sociais? E, por fim, quais são os limites e as possibilidades da história oral?

Tais questionamentos tiveram por objetivo sondar e perceber o conhecimento prévio dos participantes. Alguns demostram certo grau de conhecimento teórico e 
metodológico da história oral, enquanto outros afirmaram desconhecer, razão pela qual optaram pelo minicurso. A partir dessa polifonia é possível depreender que, embora, haja uma vasta produção sobre a temática, ainda há muita curiosidade sobre o como fazer e o como proceder na pesquisa de campo, especialmente para os que vão enveredar pelo caminho da pesquisa tendo a $\mathrm{HO}$ como recurso metodológico.

Assim, como ponto de partida, assume-se a $\mathrm{HO}$ como um procedimento metodológico, no qual tem por finalidade (re)construir fontes e documentos a partir do registro de narrativas. Essas narrativas apresentam testemunhos, versões e interpretações do narrador sobre o passado em suas múltiplas dimensões (DELGADO, 2006).

Alessandro Portelli (2016, p. 9) observa que "as fontes orais do historiador são narrativas individuais, informacionais, dialógicas, criadas no encontro entre historiador e narrador". Assim, Portelli reconhece que a história oral é a arte da escuta. Essa escuta sensível envolve respeito e empatia já que as narrativas não só revelam só o evento em si, mas desvela os significados e as representações empregados pelo narrador no ato de narrar. Por essa razão, o autor afirma que, "[...] a história oral diz respeito ao significado histórico da experiencia pessoal, por um lado, e ao impacto pessoal das questões históricas, por outro" (PORTELLI, 2016, p. 16).

Essa discussão serviu como fio de Ariadne para problematizar a relação que há, a partir das narrativas, a relação entre história, tempo e memória, ainda mais porque Delgado (2006, p. 17) assevera que,

História, tempo e memória são processos interligados. Todavia, o tempo da memória ultrapassa o tempo de vida individual e encontra-se com tempo da História [...]. A memória ativa é um recurso importante para a transmissão de experiências consolidas ao longo de diferentes temporalidades"

Essa relação entre história, tempo e memória são mais percebidos na forma da/na narração oral. Em vista disso, Portelli (2010, p. 19) chama atenção para o que ele chamou de "conteúdos da memória", os quais no entender do autor "são evocados e organizados verbalmente no dialogo interativo entre fonte e historiador, entrevistado e entrevistador".

Aqui foi possível discutir como a presença do pesquisador/entrevistador pode influenciar ou estimular as memórias dos narradores. Contudo, isso não significa dizer que os narradores só dirão o que o entrevistador deseja ouvir. Não! A memória é 
seletiva. A invocação do passado não neutra ou inócua. Em função disso, Portelli (2010, p. 18) discorre que,

[...] o que faz com que as fontes orais sejam importantes e fascinantes é precisamente o fato de que elas não recordam passivamente os fatos, mas elaboram a partir deles e criam significados através do trabalho de memória e do filtro da linguagem [...].

Diante dessa relação dialógica entre memória e linguagem, se faz necessário, também, observar e reconhecer que as fontes orais são fontes narrativas. Narrativas que são construídas e verbalizadas com e pela linguagem. Por conseguinte, Portelli (2010, p. 20) interpreta a forma narrativa a partir que ela "contém mais camadas de significado, mais caminhos de interpretação do que análise lógica, raciona".

Ao reconhecer essas camadas e estes caminhos, nos apoiamos em Delgado (2003; 2006) para apontar alguns caminhos e possibilidades para os pesquisadores/pesquisadoras iniciantes. Dentre a miríade de possibilidades, destacam-se:

a) Revela novos campos e temas de pesquisa;

b) Apresenta novas hipóteses e versões sobre processos já analisados e conhecidos;

c) Recupera memórias locais, comunitárias, étnicas, gênero ...;

d) Possibilita o registro de versões alternativas às histórias predominantes.

Muitas são as possibilidades. Contudo, a HO não responde as todas as questões de pesquisa. A sua aplicabilidade metodológica também tem percalços e dificuldades. Dentre elas, podemos, sinteticamente, pontuar algumas:

a) Aplicabilidade para pesquisas de épocas contemporâneas (tempo presente);

b) Predomínio da subjetividade do narrador;

c) Possível influência, mesmo que involuntária, do transcritor da entrevista;

d) Influência da conjuntura sobre o documento produzido;

e) Dificuldade de se registrar expressões de rosto e emoções no documento escrito.

As dificuldades e/ou obstáculos não podem ser empecilho. Cabe ao pesquisador (a) buscar formas ou estratégias para dirimi-las. Mas, creio que é bom observar a metodologia da $\mathrm{HO}$ não é um fim em si mesma, ela é um meio de constituir fontes históricas por meio das fontes orais. Para isso, assevera-se a importância da clareza do problema de pesquisa e dos objetivos. É a partir dessa definição e clareza 
que se percebe qual (ou quais) caminhos metodológicos caberá melhor para o percurso a minha pesquisa.

Essa perspectiva é importante porque não é a metodologia que define o problema da pesquisa e nem os objetivos. Mas é o caminho inverso. Ou seja, é a problematização e os objetivos que auxiliam na definição/escolha da (s) metodologia (s) mais adequada (s). Feito este processo e, se for o caso da escolha da metodologia da história oral pelo pesquisador (a), ainda assim, se faz necessário observar outras etapas que são também importantes, dentre elas: qual é o tipo de entrevista? Será uma trajetória de vida ou uma história temática? Tenho acesso aos meus possíveis interlocutores? Quais são os critérios de inclusão e exclusão dos sujeitos da/na pesquisa? As entrevistas serão semiestruturas ou estruturadas? Qual será o equipamento para a gravação da entrevista? Tenho domínio desse equipamento?

Muitos são os questionamentos pontuados acima. No entanto, eles se fazem oportunos porque é na realização da entrevista que de fato ocorre o fazer da história oral, como pontual Alberti (1990). De acordo com a autora, é na entrevista que "convergem os investimentos iniciais da implantação do projeto de pesquisa, e é de lá que partem os esforços de tratamento do acervo" (ALBERTI, 1990, p. 45).

Sobre o tratamento, abro um pequeno comentário (na verdade este tema demandaria um esforço maior de problematização e de dialogicidade) a partir da figura abaixo:

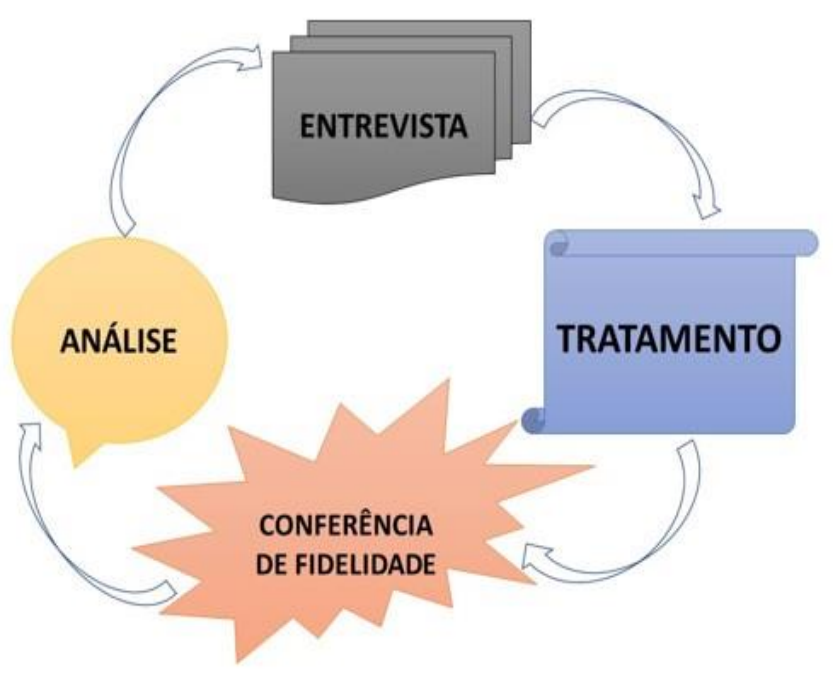

Figura 1 - Ciclo da metodologia da História Oral

Fonte: Criação do próprio autor, 2021. 
Como já foi mencionado ao longo do texto, metodologia da história oral não é um fim em si mesma, mas é um meio que tem como contexto um feixe de significados e teias de conexões através da narrativa. Assim, a figura anterior mostra que a $\mathrm{HO}$ tem um ciclo de complementariedade, que parte da entrevista e segue para o tratamento, no qual consiste na transcrição da entrevista e que se tornará num texto escrito. Uma vez feito a transcrição é importante conferir se o texto narrativo é fiel a ao texto transcrito pelo pesquisador (a). É, somente, a partir desse percurso que se tem as bases de análise das narrativas das fontes orais.

\section{4. À guisa de considerações finais}

A limitação do tamanho do texto não permitiu um aprofundamento maior e melhor sobre a metodologia da história oral. Mas, isso é fácil de resolver, até porque há vasta produção sobre esta metodologia, a qual é percebida por seu caráter interdisciplinar. Ou seja, a $\mathrm{HO}$ não é uma prerrogativa do métier do historiador ou historiadora.

A ideia por meio de um texto escrito a experiência que advinda do minicurso que aconteceu por ocasião da II Jornada de Gênero, Cultura e Deslocamentos, da Universidade Estadual de Roraima. Nele houve a participação de diferentes pessoas, diversos cursos (graduação e pós-graduação) e também geracional. Em grande medida, a participação também contou com participantes de vários estados brasileiros e, também, fora do País. Essa participação, foi favorecida pela oferta do curso ser na modalidade remota através do Google Meet.

Ao final o que se pode depreender é que a metodologia da História Oral oferece miríade de possibilidades como também tem suas limitações, especialmente porque sua aplicabilidade só é possível com pessoas contemporâneas do pesquisador (a). Essa aproximação pode interferir, ainda que involuntária, por parte do pesquisador na hora de transcrever as entrevistas.

Ademais, as entrevistas são mediadas pela memória e pela linguagem. Assim, o pesquisador (a) precisará desenvolver a "arte da escuta" e não deixar sobressair a sua visão de mundo até porque a prerrogativa da narrativa é do interlocutor e não do entrevistador.

Por fim, a entrevista e a escolha da metodologia da história oral demandam do pesquisador (a) algumas questões, tais como: toda entrevista envolve uma relação humana. Assim, se faz importante respeitar os momentos de silêncio, os 
esquecimentos ou choro que as lembranças podem despertar no narrador. Por conseguinte, as lembranças narradas são construções do presente sobre o passado, por tanto a narrativa por vezes tem sua própria logica narrativa que não respeitará uma temporalidade cronológica e temporal.

Não menos importante, dependendo da instituição, será preciso cadastrar ${ }^{2} \mathrm{e}$ submeter, antes de fazer as entrevistas, o projeto de pesquisa juntamente com a assinatura do (a) orientador (a) mais o roteiro de entrevista junto a Plataforma Brasil ${ }^{3}$ a fim de receber a anuência com Comitê de Ética em Pesquisa (CEP). Esse procedimento é importante porque a pesquisa com a $\mathrm{HO}$ tem por exigência a participação de seres humanos.

\section{Referências.}

ALBERTI, Verena. Ouvir contar: textos em História Oral. Reimpressão. Rio de Janeiro: Editora FGV, 2007.

ALBERTI, Verena. Histórias dentro da história. In: Fontes históricas. $3^{\underline{a}}$ ed. São Paulo: Contexto, 2014, p. 155-202.

DELGADO, Lucilia de Almeida Neves. História oral e narrativa: tempo, memória e identidades. In: Revista de História Oral. v. 6 (2003), p. 9-25.

DELGADO, Lucilia de Almeida Neves. História Oral: memória, tempo, identidades. Belo Horizonte/MG: Autêntica, 2006.

MONTENEGRO, Antônio Torres. História Oral e memória: a cultura popular revisitada. 5. ed. São Paulo: Contexto, 2003.

PORTELLI, Alessandro. O que faz a história oral diferente. (Trad.) Maria Therezinha Janine Ribeiro. In: Projeto História, São Paulo (14), Fev., 1997.

PORTELLI, Alessandro. A lógica das narrativas e a aprendizagem da diferença na pesquisa de campo. In: Oralidade e subjetividade: os meandros infinitos da memória. (Org's) Dulce Consuelo Andreatta Whitaker; Thelma Maria Grisi Velôso. Campinas Grande/PB: EDUEP, 2005.

PORTELLI, Alessandro. Sempre existe uma barreira: a arte multivocal da história oral. In: Ensaios de história oral. São Paulo: Letra e Voz, 2010, p. 19-35.

PORTELLI, Alessandro. História Oral como arte da escuta. São Paulo: Letra e Voz, 2016

\footnotetext{
2 O cadastro deve ser feito no site: http://plataformabrasil.saude.gov.br/login.jsf

${ }^{3}$ A Plataforma Brasil é uma base nacional e unificada de registros de pesquisas envolvendo seres humanos para todo o sistema CEP/CONEP.
} 